Journal of Mathematics and Statistics 7 (1): 78-80, 2011

ISSN 1549-3644

(C) 2010 Science Publications

\title{
Remark on Bi-Ideals and Quasi-Ideals of Variants of Regular Rings
}

\author{
${ }^{1}$ Samruam Baupradist and ${ }^{2,3}$ Ronnason Chinram \\ ${ }^{1}$ Department of Mathematics, Chulalongkorn University, Bangkok 10330, Thailand \\ ${ }^{2}$ Department of Mathematics and Statistics, \\ Prince of Songkla University, Hat Yai, Songkhla 90110, Thailand \\ ${ }^{3}$ Centre of Excellence in Mathematics, CHE, Si Ayuthaya Road, \\ Bangkok 10400, Thailand
}

\begin{abstract}
Problem statement: Every quasi-ideal of a ring is a bi-ideal. In general, a bi-ideal of a ring need not be a quasi-ideal. Every bi-ideal of regular rings is a quasi-ideal, so bi-ideals and quasi-ideals of regular rings coincide. It is known that variants of a regular ring need not be regular. The aim of this study is to study bi-ideals and quasi-ideals of variants of regular rings. Approach: The technique of the proof of main theorem use the properties of regular rings and bi-ideals. Results: It shows that every bi-ideal of variants of regular rings is a quasi-ideal. Conclusion: Although the variant of regular rings need not be regular but every bi-ideal of variants of regular rings is a quasi-ideal.
\end{abstract}

Key words: Bi-ideals, quasi-ideals, variants, regular rings, BQ-rings

\section{INTRODUCTION}

The notion of quasi-ideals in rings was introduced by (Steinfeld, 1953) while the notion of bi-ideals in rings was introduced much later. It was actually introduced (Lajos and Sza'sz, 1971).

For nonempty subsets $\mathrm{A}, \mathrm{B}$ of a ring $\mathrm{R}, \mathrm{AB}$ denotes the set of all finite sums of the form $\sum \mathrm{a}_{\mathrm{i}} \mathrm{b}_{\mathrm{i}}, \mathrm{a}_{\mathrm{i}} \in \mathrm{A}, \mathrm{b}_{\mathrm{i}} \in \mathrm{B}$. A subring $\mathrm{Q}$ of a ring $\mathrm{R}$ is called $\mathrm{a}$ quasi-ideal of $\mathrm{R}$ if $\mathrm{RQ} \cap \mathrm{QR} \subseteq \mathrm{Q}$ and a bi-ideal of $\mathrm{R}$ is a subring $\mathrm{B}$ of $\mathrm{R}$ such that $\mathrm{BRB} \subseteq \mathrm{B}$. Every quasi-ideal of $\mathrm{R}$ is a bi-ideal. In general, bi-ideals of rings need not be quasi-ideals. See the following example. Consider the ring $\left(\mathrm{SU}_{4}(\mathbb{R}),+, \cdot\right)$ of all strictly upper triangular $4 \times 4$ matrices over the field $\mathbb{R}$ of real numbers under the usual addition and multiplication of matrices.

Let $B=\left\{\left[\begin{array}{cccc}0 & 0 & x & 0 \\ 0 & 0 & 0 & x \\ 0 & 0 & 0 & 0 \\ 0 & 0 & 0 & 0\end{array}\right] \mid x \in \mathbb{R}\right\}$.

Then $\mathrm{B}$ is a zero subring of $\left(\mathrm{SU}_{4}(\mathbb{R}),+, \cdot\right)$. Moreover, $\mathrm{BSU}_{4}(\mathbb{R}) \mathrm{B}=\{0\}$. Thus $\mathrm{B}$ isa bi-ideal of $\left(\mathrm{SU}_{4}(\mathbb{R}),+, \cdot\right)$.

But

$$
\begin{aligned}
& {\left[\begin{array}{llll}
0 & 0 & 0 & 1 \\
0 & 0 & 0 & 0 \\
0 & 0 & 0 & 0 \\
0 & 0 & 0 & 0
\end{array}\right]=\left[\begin{array}{llll}
0 & 1 & 0 & 0 \\
0 & 0 & 0 & 0 \\
0 & 0 & 0 & 0 \\
0 & 0 & 0 & 0
\end{array}\right]\left[\begin{array}{llll}
0 & 0 & 1 & 0 \\
0 & 0 & 0 & 1 \\
0 & 0 & 0 & 0 \\
0 & 0 & 0 & 0
\end{array}\right]} \\
& =\left[\begin{array}{llll}
0 & 0 & 1 & 0 \\
0 & 0 & 0 & 1 \\
0 & 0 & 0 & 0 \\
0 & 0 & 0 & 0
\end{array}\right]\left[\begin{array}{llll}
0 & 0 & 0 & 0 \\
0 & 0 & 0 & 0 \\
0 & 0 & 0 & 1 \\
0 & 0 & 0 & 0
\end{array}\right] \\
& \in\left(\mathrm{SU}_{4}(\mathbb{R}) \mathrm{B} \cap \mathrm{BSU}_{4}(\mathbb{R})\right) \backslash \mathrm{B} .
\end{aligned}
$$

So B is not a quasi-ideal of $\left(\mathrm{SU}_{4}(\mathbb{R}),+, \cdot\right)$.

\section{MATERIALS AND METHODS}

An element a of a ring $\mathrm{R}$ is called regular if there exists $\mathrm{x}$ in $\mathrm{S}$ such that $\mathrm{a}=\mathrm{axa}$. A ring $\mathrm{R}$ is called regular if every element in $\mathrm{R}$ is regular. The following known result shows a sufficient condition for a bi-ideal of a ring to be a quasi-ideal.

Theorem 1: If $B$ is a bi-ideal of a ring $R$ such that every element of $B$ is regular in $R$, then $B$ is a quasiideal of $\mathrm{R}$. In particular, if $\mathrm{R}$ is a regular ring, then every bi-ideal of $\mathrm{R}$ is a quasi-ideal.

Let $\mathrm{R}$ be a ring and $\mathrm{a} \in \mathrm{R}$. A new product $\mathrm{o}$ defined on $\mathrm{R}$ by $\mathrm{x}$ o $\mathrm{y}=$ xay for all $\mathrm{x}, \mathrm{y} \in \mathrm{R}$. Then $(\mathrm{R},+, \mathrm{o})$ is a

Corresponding Author: Samruam Baupradist, Department of Mathematics, Chulalongkorn University, Bangkok 10330, Thailand 
ring. We usually write $(\mathrm{R},+, \mathrm{a})$ rather that $(\mathrm{R},+, \mathrm{o})$ to make the element a explicit. The ring $(\mathrm{R},+, \mathrm{a})$ is called a variant of $\mathrm{R}$ with respect to $\mathrm{a}$. It is well-known that the variant of regular rings need not be regular ring (see (Kemprasit, 2002) and (Chinram, 2009).

Our aim is to prove that every bi-ideal of variants of regular rings is a quasi-ideal. In fact, the technique of the proof of Theorem 1 is helpful for our work. However, our proof is more complicated.

\section{RESULTS}

The following theorem is our main result.

Theorem 2: Let $\mathrm{R}$ be a regular ring and $\mathrm{a} \in \mathrm{R}$. Then every bi-ideal of the ring $(\mathrm{R},+, \mathrm{a})$ is a quasi-ideal.

Proof: Let $B$ be a bi-ideal of a ring $(\mathrm{R},+, \mathrm{a})$. Then $\mathrm{BaRaB} \subseteq \mathrm{B}$. To show that $\mathrm{RaB} \cap \mathrm{BaR} \subseteq \mathrm{B}$, let $\mathrm{x}$ be an element of $\mathrm{RaB} \cap \mathrm{BaR}$.

Then:

$\mathrm{x} \in \mathrm{RaB}$

and

$\mathrm{x}=\mathrm{b}_{11} \mathrm{ar}_{1}+\mathrm{b}_{12} \mathrm{ar}_{2}+\ldots+\mathrm{b}_{1 \mathrm{n}} \mathrm{ar}_{\mathrm{n}}$

for some $b_{11}, b_{12} \ldots, b_{1 n} \in B$ and $r_{1}, r_{2}, \ldots, r_{n} \in R$.

Since each $b_{1 i} a \in R$ and $(R,+, \cdot)$ is a regular ring, there exists $s_{1 i} \in R$ such that $b_{1 i} a=b_{1 i} a_{1 i} b_{1 i}$ a. By (2), we have:

$\mathrm{x}=\mathrm{b}_{11} \mathrm{as}_{11} \mathrm{~b}_{11} \mathrm{ar}_{11}+\mathrm{b}_{12} \mathrm{as}_{12} \mathrm{~b}_{12} \mathrm{ar}_{2}+\ldots+\mathrm{b}_{1 \mathrm{n}} \mathrm{as}_{1 \mathrm{n}} \mathrm{b}_{1 \mathrm{n}} \mathrm{ar}_{\mathrm{n}}$

and

$\mathrm{b}_{11} \mathrm{as}_{11} \mathrm{~b}_{11} \mathrm{ar}_{1}=\mathrm{b}_{11} \mathrm{as}_{11}\left(\mathrm{x}-\mathrm{b}_{12} \mathrm{ar}_{2}-\ldots-\mathrm{b}_{1 \mathrm{n}} \mathrm{ar}_{\mathrm{n}}\right)$

$=\mathrm{b}_{11} \mathrm{as}_{11} \mathrm{x}-\mathrm{b}_{11} \mathrm{as}_{11} \mathrm{~b}_{12} \mathrm{ar}_{2}-\ldots-\mathrm{b}_{11} \mathrm{as}_{11} \mathrm{~b}_{1 \mathrm{n}} \mathrm{ar}_{\mathrm{n}}$.

It then follows from (3) and (4) that:

$\mathrm{x}=\mathrm{b}_{11} \mathrm{as}_{11} \mathrm{x}+\left(\mathrm{b}_{12} \mathrm{as}_{12} \mathrm{~b}_{12}-\mathrm{b}_{11} \mathrm{as}_{11} \mathrm{~b}_{12}\right) \mathrm{ar}_{2}$

$+\ldots+\left(b_{1 n} a_{1 n} b_{1 n}-b_{11} a_{11} b_{1 n}\right) a r_{n}$.

But from (1) and (2):

$\mathrm{b}_{11} \mathrm{as}_{11} \mathrm{x} \in \mathrm{Bas}_{11} \mathrm{RaB} \subseteq \mathrm{BaRaB}$ and for $i \in\{2,3, \ldots, n\}$,

$\mathrm{b}_{1 \mathrm{i}} \mathrm{as}_{1 \mathrm{i}} \mathrm{b}_{1 \mathrm{i}}-\mathrm{b}_{1} \mathrm{as}_{11} \mathrm{~b}_{1 \mathrm{i}} \in \mathrm{Bas}_{1 \mathrm{i}} \mathrm{B}-\mathrm{Bas}_{11} \mathrm{~B} \subseteq \mathrm{BaR}$.

So:

$\mathrm{x}=\mathrm{b}_{1}+\mathrm{b}_{22} \mathrm{ar}_{2}+\ldots+\mathrm{b}_{2 \mathrm{n}} \mathrm{ar}_{\mathrm{n}}$

for some $\mathrm{b}_{1} \in \mathrm{BaRaB}$ and $\mathrm{b}_{22}, \ldots, \mathrm{b}_{2 \mathrm{n}} \in \mathrm{BaR}$.

Since for $i \in\{2,3, \ldots, n\}, b_{2 i} a \in R$, we have that for each $i \in\{2,3, \ldots, n\}, b_{2 i} a=b_{2 i} a_{2 i} b_{2 i} a$ for some $s_{2 i} \in R$. Thus from (5),

$\mathrm{x}=\mathrm{b}_{1}+\mathrm{b}_{22} \mathrm{as}_{22} \mathrm{~b}_{22} \mathrm{ar}_{2}+\ldots+\mathrm{b}_{2 \mathrm{n}} \mathrm{as}_{2 \mathrm{n}} \mathrm{b}_{2 \mathrm{n}} \mathrm{ar}_{\mathrm{n}}$

and

$\mathrm{b}_{22} \mathrm{as}_{22} \mathrm{~b}_{22} \mathrm{ar}_{2}=\mathrm{b}_{22} \mathrm{as}_{22}\left(\mathrm{x}-\mathrm{b}_{1}-\mathrm{b}_{23} \mathrm{ar}_{3}-\ldots-\mathrm{b}_{2 \mathrm{n}} \mathrm{ar}_{\mathrm{n}}\right)$

$=b_{22} a_{22} x-b_{22} a_{22} b_{1}-b_{22} a_{22} b_{23} a r_{3}$

$-\ldots-\mathrm{b}_{22} \mathrm{as}_{22} \mathrm{~b}_{2 \mathrm{n}} \mathrm{ar}_{\mathrm{n}}$.

We then deduce from (6) and (7) that:

$\mathrm{x}=\mathrm{b}_{1}+\mathrm{b}_{22} \mathrm{as}_{22} \mathrm{x}-\mathrm{b}_{22} \mathrm{as}_{22} \mathrm{~b}_{1}$

$+\left(\mathrm{b}_{23} \mathrm{as}_{23} \mathrm{~b}_{23}-\mathrm{b}_{22} \mathrm{as}_{22} \mathrm{~b}_{23}\right) \mathrm{ar}_{2}$

$+\ldots+\left(b_{2 n} a_{2 n} b_{2 n}-b_{22} a_{22} b_{2 n}\right) a_{n}$

But from (1) and (5):

$\mathrm{b}_{1} \in \mathrm{BaRaB}$,

$\mathrm{b}_{22} \mathrm{as}_{22} \mathrm{x} \in \mathrm{BaRas}_{22} \mathrm{RaB} \subseteq \mathrm{BaRaB}$,

$\mathrm{b}_{22} \mathrm{as}_{22} \mathrm{~b}_{1} \in$ BaRas $_{22} \mathrm{BaRaB} \subseteq \mathrm{BaRaB}$

and for $i \in\{3, \ldots, n\}$,

$\mathrm{b}_{2 \mathrm{i}} \mathrm{as}_{2 \mathrm{i}} \mathrm{b}_{2 \mathrm{i}}-\mathrm{b}_{22} \mathrm{as}_{22} \mathrm{~b}_{21}$

$\in \operatorname{BaRas}_{2 \mathrm{i}} \mathrm{BaR}+\mathrm{BaRas}_{22} \mathrm{BaR}$.

Thus $\mathrm{b}_{2 \mathrm{i}} \mathrm{as}_{2 \mathrm{i}} \mathrm{b}_{2 \mathrm{i}}-\mathrm{b}_{22} \mathrm{as}_{22} \mathrm{~b}_{21} \in \mathrm{BaR}$, so we have:

$\mathrm{x}=\mathrm{b}_{2}+\mathrm{b}_{33} \mathrm{ar}_{3}+\ldots+\mathrm{b}_{3 \mathrm{n}} \mathrm{ar}_{\mathrm{n}}$

for some $b_{2} \in B a R a B$ and $b_{33}, \ldots, b_{3 n} \in B a R$. that:

Continuing in this fashion, we obtain the $n-1^{\text {th }}$ step 
$\mathrm{x}=\mathrm{b}_{\mathrm{n}-1}+\mathrm{b}_{\mathrm{nn}} \mathrm{ar}_{\mathrm{n}}$

for some $\mathrm{b}_{\mathrm{n}-1} \in \mathrm{BaRaB}$ and $\mathrm{b}_{\mathrm{nn}} \in \mathrm{BaR}$.

Let $\mathrm{s}_{\mathrm{nn}} \in \mathrm{R}$ be such that $\mathrm{b}_{\mathrm{nn}} \mathrm{a}=\mathrm{b}_{\mathrm{nn}} \mathrm{as}_{\mathrm{nn}} \mathrm{b}_{\mathrm{nn}} \mathrm{a}$. Then from (8):

$\mathrm{x}=\mathrm{b}_{\mathrm{n}-1}+\mathrm{b}_{\mathrm{nn}} \mathrm{as}_{\mathrm{nn}} \mathrm{b}_{\mathrm{nn}} \mathrm{ar}_{\mathrm{n}}$

and

$\mathrm{b}_{\mathrm{nn}} \mathrm{as}_{\mathrm{nn}} \mathrm{b}_{\mathrm{nn}} \mathrm{as}_{\mathrm{nn}} \mathrm{b}_{\mathrm{nn}} \mathrm{ar}_{\mathrm{n}}=\mathrm{b}_{\mathrm{nn}} \mathrm{as}_{\mathrm{nn}}\left(\mathrm{x}-\mathrm{b}_{\mathrm{n}-1}\right)$

$=\mathrm{b}_{\mathrm{nn}} \mathrm{as}_{\mathrm{nn}} \mathrm{x}-\mathrm{b}_{\mathrm{nn}} \mathrm{as}_{\mathrm{nn}} \mathrm{b}_{\mathrm{n}-1}$.

Thus we obtain from (9) and (10) that:

$\mathrm{x}=\mathrm{b}_{\mathrm{n}-1}+\mathrm{b}_{\mathrm{nn}} \mathrm{as}_{\mathrm{nn}} \mathrm{x}-\mathrm{b}_{\mathrm{nn}} \mathrm{as}_{\mathrm{nn}} \mathrm{b}_{\mathrm{n}-1}$.

But since by (1) and (8):

$\mathrm{b}_{\mathrm{n}-1} \in \mathrm{BaRaB}$,

$\mathrm{b}_{\mathrm{nn}}$ as $_{\mathrm{nn}} \mathrm{x} \in \mathrm{BaRas}_{\mathrm{nn}} \mathrm{RaB} \subseteq \mathrm{BaRaB}$ and

$\mathrm{b}_{\mathrm{nn}} \mathrm{as}_{\mathrm{nn}} \mathrm{b}_{\mathrm{n}-1} \in \mathrm{BaRas}_{\mathrm{nn}} \mathrm{BaRaB} \subseteq \mathrm{BaRaB}$,

it follows that $\mathrm{x} \in \mathrm{BaRaB}$ which implies that $\mathrm{x} \in \mathrm{B}$.

This proves that $\mathrm{RaB} \cap \mathrm{BaR} \subseteq \mathrm{B}$, so $\mathrm{B}$ is a quasiideal of the ring $(\mathrm{R},+, \mathrm{a})$.

Hence the theorem is proved.

\section{DISCUSSION}

It is known that every bi-ideal of regular rings is a quasi-ideal. However, although the variant of regular rings need not be a regular ring but every bi-ideal of variants of regular rings is a quasi-ideal.

\section{CONCLUSION}

Every bi-ideal of variants of regular rings is a quasi-ideal, so bi-ideals and quasi-ideals of variants of regular rings coincide.

\section{REFERENCES}

Chinram, C., 2009. Regularity-preserving elements of regular rings. Sci. Asia, 35: 111-112. DOI: 10.2306/scienceasia1513-1874.2009.35.111

Kemprasit, Y., 2002. Regularity and unit-regularity of generalized semigroups of linear transformations. Southeast Asian Bull. Math., 25: 617-622. DOI: 10.1007/s100120200006

Kemprasit Y. and S. Baupradist, 2001. A note on the multiplicative semigroups $Z_{n}$ whose bi-ideals are quasi-ideals. Southeast Asian Bull. Math., 25: 269-271. DOI: 10.1007/s10012-001-0269-9

Lajos, S. and F.A. Sza'sz, 1970. On the bi-ideals in associative rings. Proc. Japan Acad., Ser. A, 46: 505-507. DOI:10.3792/pja/1195520265

Steinfeld, O., 1953. On ideal-quotients and prime ideals. Acta Math. Acad. Sci. Hung., 4: 289-298. DOI: $10.1007 / \mathrm{BF} 02127587$ 